\title{
A Low-Cost Sustainable Energy Solution for Pristine Mountain Areas of Developing Countries
}

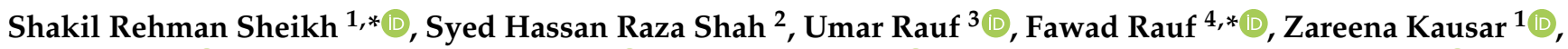 \\ Umair Aziz ${ }^{1}\left(\mathbb{0}\right.$, Muhammad Faizan Shah ${ }^{5}{ }^{(\mathbb{C}}$, Haseeb Yaqoob ${ }^{5}(\mathbb{D})$ and Muhammad Bilal Khan Niazi ${ }^{6}$ \\ 1 Department of Mechatronics Engineering, Sector E-9, Air University, Islamabad 44000, Pakistan; \\ Zareena.Kausar@mail.au.edu.pk (Z.K.); Umair.Aziz@mail.au.edu.pk (U.A.) \\ 2 Aerospace Engineering Department, Samuel Ginn College of Engineering, Auburn University, \\ Auburn, AL 36849, USA; Szs0196@auburn.edu \\ 3 Department of Mechanical Engineering, Bilkent University, 06800 Ankara, Turkey; Umar.rauf@bilkent.edu.tr \\ 4 College of Business, Engineering and Technology, Texas A\&M University-Texarkana, \\ Texarkana, TX 75503, USA \\ 5 Department of Mechanical Engineering, Khwaja Fareed University of Engineering \& Information Technology, \\ Rahim Yar Khan 64200, Pakistan; faizan.shah@kfueit.edu.pk (M.F.S.); Haseeb.yaqoob@kfueit.edu.pk (H.Y.) \\ 6 Department of Chemical Engineering, School of Chemical and Materials Engineering, National University of \\ Sciences and Technology, Islamabad 44000, Pakistan; m.b.k.niazi@scme.nust.edu.pk \\ * Correspondence: shakilrs@mail.au.edu.pk (S.R.S.); frauf@tamut.edu (F.R.)
}

Citation: Sheikh, S.R.; Shah, S.H.R.; Rauf, U.; Rauf, F.; Kausar, Z.; Aziz, U.; Shah, M.F.; Yaqoob, H.; Niazi, M.B.K. A Low-Cost Sustainable Energy Solution for Pristine Mountain Areas of Developing Countries. Energies 2021, 14, 3160. https://doi.org/ $10.3390 /$ en14113160

Academic Editor: Chirag Trivedi

Received: 25 April 2021

Accepted: 27 May 2021

Published: 28 May 2021

Publisher's Note: MDPI stays neutral with regard to jurisdictional claims in published maps and institutional affiliations.

Copyright: (c) 2021 by the authors. Licensee MDPI, Basel, Switzerland. This article is an open access article distributed under the terms and conditions of the Creative Commons Attribution (CC BY) license (https:// creativecommons.org/licenses/by/ $4.0 /)$.

\begin{abstract}
The rise in energy requirements and its shortfall in developing countries have affected socioeconomic life. Communities in remote mountainous regions in Asia are among the most affected by energy deprivation. This study presents the feasibility of an alternate strategy of supplying clean energy to the areas consisting of pristine mountains and forest terrain. Southeast Asia has a much-diversified landscape and varied natural resources, including abundant water resources. The current study is motivated by this abundant supply of streams which provides an excellent environment for run-of-river micro vertical axis water turbines. However, to limit the scope of the study, the rivers and streams flowing in northern areas of Pakistan are taken as the reference. The study proposes a comprehensive answer for supplying low-cost sustainable energy solutions for such remote communities. The suggested solution consists of a preliminary hydrodynamic design using Qblade, further analysis using numerical simulations, and finally, experimental testing in a real-world environment. The results of this study show that the use of microturbines is a very feasible option considering that the power generation density of the microturbine comes out to be approximately $2100 \mathrm{kWh} /$ year $/ \mathrm{m}^{2}$, with minimal adverse effects on the environment.
\end{abstract}

Keywords: run-of-the-river power generation; vertical axis water turbine (VAWT); remote communities; micro-hydro power; sustainability

\section{Introduction}

Renewable, or inexpensive energy resources, are the need of the day for the sustainment of daily life [1]. Hydroelectric energy is one of the most abundantly available resource of renewable energy in Southeast Asia, but traditional hydroelectric projects require a huge amount of investment in the form of infrastructure and time. Most rivers/streams originating from the mountainous regions of Southeast Asia, such as the Himalayan ranges, are shallow, but they keep a high velocity during the majority of the year. Within the region, several countries like Pakistan have a large number of such water channels. These are in abundance in the northern part of Pakistan's rain catchment areas. To limit the scope of the current study, data from the water channels located in Pakistan are taken as the reference. The main aim of this study is to find a possible solution to provide energy to small local communities residing on the banks of these water streams, without disrupting the local ecology. The preliminary hydrodynamic design is made after basic parametric analyses 
using QBlade. The designed turbine is then validated using numerical simulations, and finally, experimental testing in a real-world environment is completed.

Though this study does not conduct environmental analyses, earlier works have shown that small run-of-the-river hydroelectric power projects do not cause any significant negative impact on the physical or chemical characteristics of the waterways [2] and innovative designs can reduce other ecological effects [3]. The geographical layout of the Indus Basin is given in Figure 1 [4]. The depicted precipitation data shows high precipitation feeding the water channels being studied in this research effort, while the flow rates of the water channels originating in the Northern Regions of Pakistan are shown in Figure 2 [5].

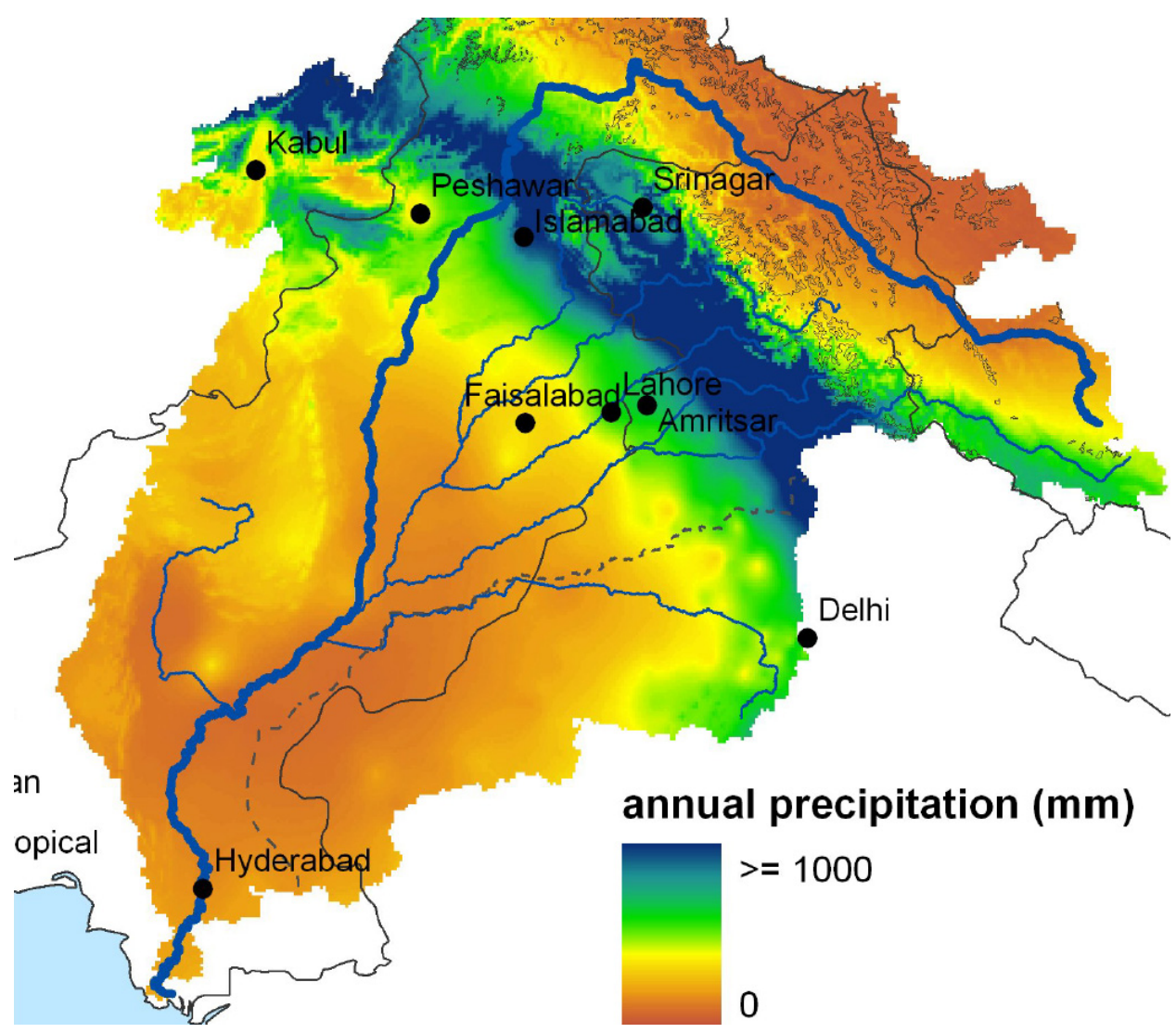

Figure 1. Climatology within the Indus basin: average annual precipitation $(\mathrm{mm})$ for the period 1950-2000 [4].

Figure 2 shows that most of these water channels have water flowrates ranging from an average flow rate of $89 \mathrm{~m}^{3} / \mathrm{s}$ during the winter and higher flowrates averaging at $473 \mathrm{~m}^{3} / \mathrm{s}$ during the summer and reaching up to highs of around $1200-1700 \mathrm{~m}^{3} / \mathrm{s}$ in peak precipitation season, as shown in Table 1.

These flow rates (Table 1) in mountain regions translate to water velocities ranging from $1.5-2.5 \mathrm{~m} / \mathrm{s}$ in the off-peak season and to $3.5-4.5 \mathrm{~m} / \mathrm{s}$ in the peak rainy season. Such water flowrates are sufficient for the year-round harvesting of hydroelectric energy. However, these water channels are mostly shallow, and during off-peak season, their depth can be less than $1.5 \mathrm{~m}$. In such a scenario, run-of-the-river micro-vertical axis water turbines $(\mu \mathrm{VAWT})$ supply a more efficient and workable solution for harnessing the kinetic energy of flowing water and converting it into electrical energy than the horizontal axis water turbine (HAWT) options [6]. 


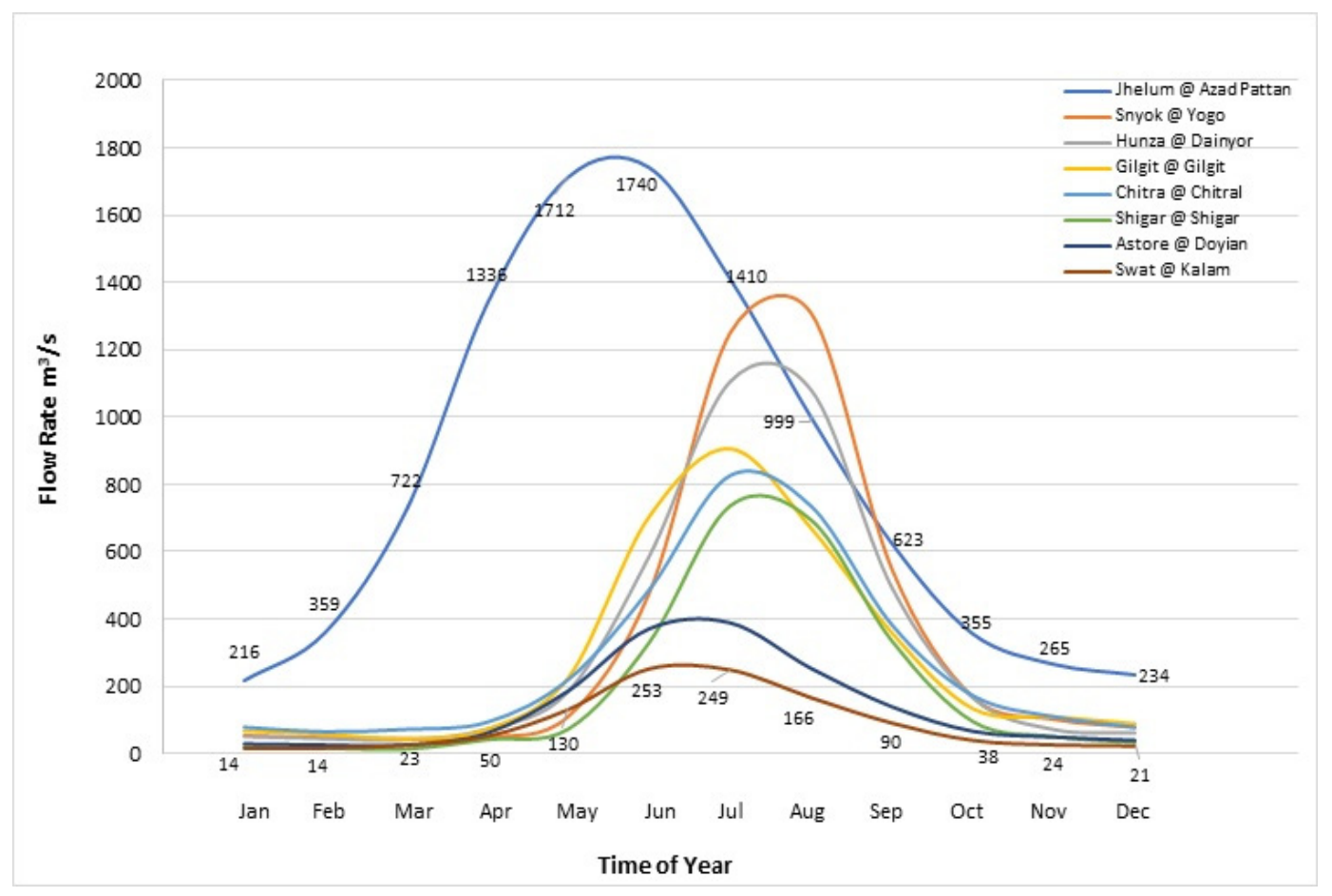

Figure 2. Flowrates of water channels in the region [5].

Table 1. Flowrates $\left(\mathrm{m}^{3} / \mathrm{s}\right)$ of rivers and streams in the region.

\begin{tabular}{|c|c|c|c|c|c|c|c|c|c|c|c|c|}
\hline River and Location & Jan & Feb & Mar & Apr & May & Jun & Jul & Aug & Sep & Oct & Nov & Dec \\
\hline Jhelum, Azad Pattan & 216 & 359 & 722 & 1336 & 1712 & 1740 & 1410 & 999 & 623 & 355 & 265 & 234 \\
\hline Snyok, Yogo & 52 & 46 & 43 & 46 & 109 & 476 & 1249 & 1309 & 546 & 167 & 101 & 77 \\
\hline Hunza, Dainyor & 52 & 46 & 43 & 74 & 186 & 587 & 1107 & 1083 & 494 & 167 & 73 & 63 \\
\hline Chitra, Chitral & 80 & 67 & 74 & 95 & 221 & 486 & 824 & 734 & 382 & 174 & 111 & 80 \\
\hline Gilgit, Gilgit & 66 & 56 & 43 & 71 & 224 & 706 & 908 & 671 & 358 & 132 & 108 & 87 \\
\hline Shigar, Shigar & 18 & 14 & 11 & 39 & 71 & 329 & 737 & 696 & 334 & 94 & 49 & 32 \\
\hline Astore, Doyian & 28 & 25 & 25 & 60 & 186 & 371 & 389 & 253 & 139 & 66 & 49 & 38 \\
\hline Swat, Kalam & 14 & 14 & 23 & 50 & 130 & 253 & 249 & 166 & 90 & 38 & 24 & 21 \\
\hline Average flowrate per month & 66 & 78 & 123 & 221 & 355 & 618 & 859 & 739 & 371 & 149 & 97 & 79 \\
\hline \multicolumn{5}{|c|}{ Average winter months flow } & 89 & & & & & & & \\
\hline \multicolumn{5}{|c|}{ Average summer months flow } & 473 & & & & & & & \\
\hline
\end{tabular}

Alternately, using fossil fuels would cause great harm to the pristine natural environment [7-10]. Hydrokinetic turbines have the advantage of a smaller footprint than other available renewable options, like solar power, which has a power density of around $0.16-0.25 \mathrm{~kW} / \mathrm{m}^{2}$ [11], and would need clearing up large forest areas. Similarly, erecting huge towers to harness wind energy can be disruptive to the natural environment [12-16]. Thus, under the existing conditions of the Southeast Asia region, exploiting the kinetic energy of flowing water seems to be the more environmentally friendly option, as it encompasses many socioeconomic benefits for the region's population as well $[17,18]$. Other than being environmentally suitable, $\mu$ VAWT also have a positive effect on the local and regional economies [19]. It is seen that providing remote off-grid areas with energy through local microgrids is both less expensive and less disruptive to the local ecology than extending the main grid to such areas [20-23]. This research effort tries to design an efficient $\mu$ VAWT model with multiple design parameters adjusted to values where the overall performance of the $\mu$ VAWT is fine-tuned to year-round energy extraction of $2.5-5 \mathrm{~kW}$ from the flowing water of rivers and streams found in the mountain regions of Pakistan. 


\section{Design of Darrieus Type Turbine}

Water turbines can be broadly categorized as horizontal axis, vertical axis, and crossflow turbines based on the axis of rotation [24]. The conventional horizontal axis and crossflow water turbines are more developed and have better efficiency compared to the vertical axis turbines, but they are not suited for shallow water channels with a water head of less than $3 \mathrm{~m}[25,26]$.

Darrieus turbines use lift force produced by hydrofoil to rotate the shaft, while Savonius turbines rotate because of the drag force experienced by the rotor. Darrieus turbines are selected for this research effort, as it can achieve higher efficiency compared to the Savonius turbines under the given conditions [27-31]. The design is simple and well suited for mountain water streams; it does not require a complex yawing mechanism and its compact nature can allow it to be portable as well. The structural design of the Darrieus $\mu \mathrm{VAWT}$ is simpler and can accommodate most mechanical parts and even the generator on top of the turbine or conveniently close to the stream bank. However, the hydrodynamic design of the rotor blades can be quite complex, as the blades experience interaction with vortices generated by preceding blades as well as the remnants of vortices generated in their earlier cycle. Engineers and researchers have developed different performance prediction models, such as the cascade, vortex, and momentum models [32-34], to analyze the power output of the $\mu$ VAWT. These models estimate relative velocities and incidence angles at every azimuthal location to calculate normal and tangential forces [35]. It is the tangential force which drives the turbine.

\section{Design Parameters}

The design of a Darrieus rotor depends upon many geometric parameters, which include rotor radius $(\mathrm{R})$, rotor height $(\mathrm{H})$, number of blades $(\mathrm{N})$, blade airfoil, blade camber, blade chord length (c), and blade pitch angle $(\phi)$. In the current study, the preliminary turbine design is based on the momentum model known as the double multiple stream tube (DMST) model. This model was developed by Paraschivoiu (2002) [35]. The open-source software QBlade, based on DMST, is used for performance evaluation.

DMST is derived from actuator disc theory and blade element theory. The energy extracted from the fluid occurs due to a reduction in the downstream velocity, or the water kinetic energy is converted to rotor mechanical energy. As shown in Figure 4, DMST models the turbine by dividing it into several tubes. Then every stream tube is further divided into two parts, i.e., upstream, and downstream. The turbine performance is separately calculated for both parts and then summed up. As shown in Figure 4, DMST considers five important velocities i.e., inflow velocity $V_{\infty}$; upwind induced velocity $V_{u}$; equilibrium velocity $\mathrm{V}_{\text {eq }}$; downwind induced velocity $\mathrm{V}_{\mathrm{d}}$; wake velocity $\mathrm{V}_{\mathrm{w}}$ [36,37]. The turbine shaft power produced is calculated as:

$$
P=C_{p} \frac{1}{2} \rho A_{r e f} V_{\infty}{ }^{3}
$$

where, $A_{\text {ref }}=2 \mathrm{RH}$ is the turbine's normal projected area.

$C_{P}$ is the turbine power coefficient, $V_{\infty}$ is the free stream (inflow) velocity, and $\rho$ is the density of the fluid. The local angle of attack $a$ is calculated using the formula:

$$
\alpha=\arctan \frac{\sin \theta}{\cos \theta+\lambda}
$$

where, $\lambda$ is an important dimensionless quantity known as the tip-speed ratio (TSR). Angle $\theta$ is an azimuthal position of the blade (see Figure 4). TSR is the ratio between the free stream water velocity $V_{\infty}$ and the blade's tangential velocity due to its rotation. $\omega$ is the angular velocity of the turbine. TSR is then given by:

$$
\mathrm{TSR}=\lambda=\frac{\omega R}{V_{\infty}}
$$




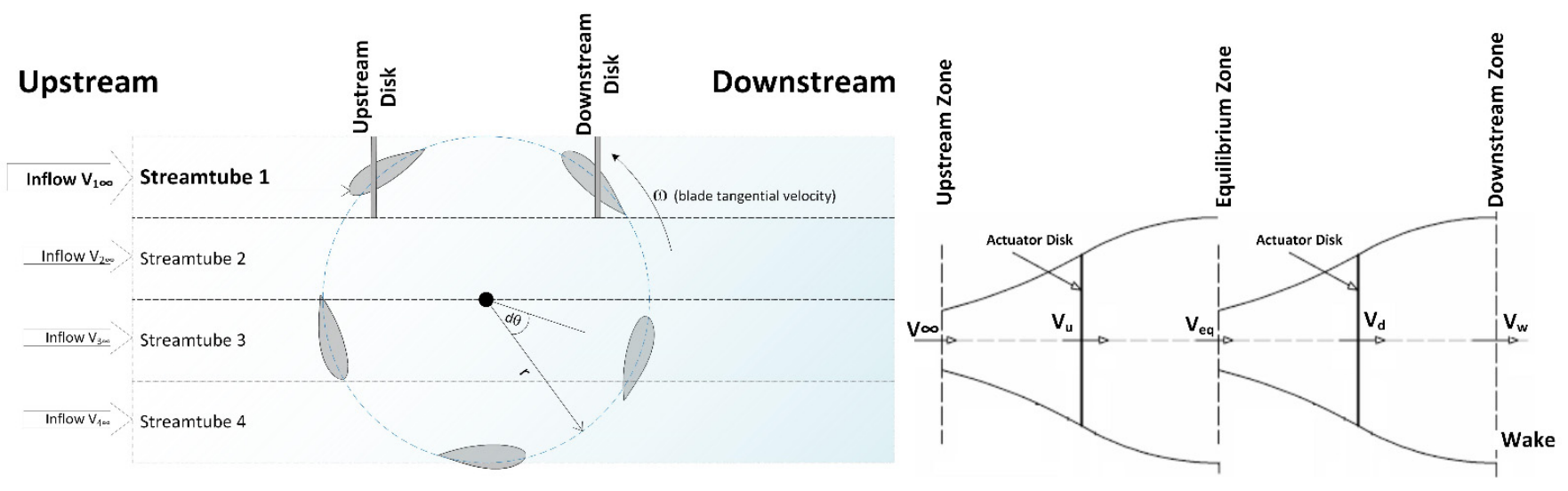

Figure 3. Double multiple stream tube model.

The relationship between the power coefficient and torque $(T)$ produced by the rotor is given below:

$$
\begin{gathered}
P=T \omega \\
C_{P}=\frac{2 T \omega}{\rho A_{r e f} V_{\infty}{ }^{3}}
\end{gathered}
$$

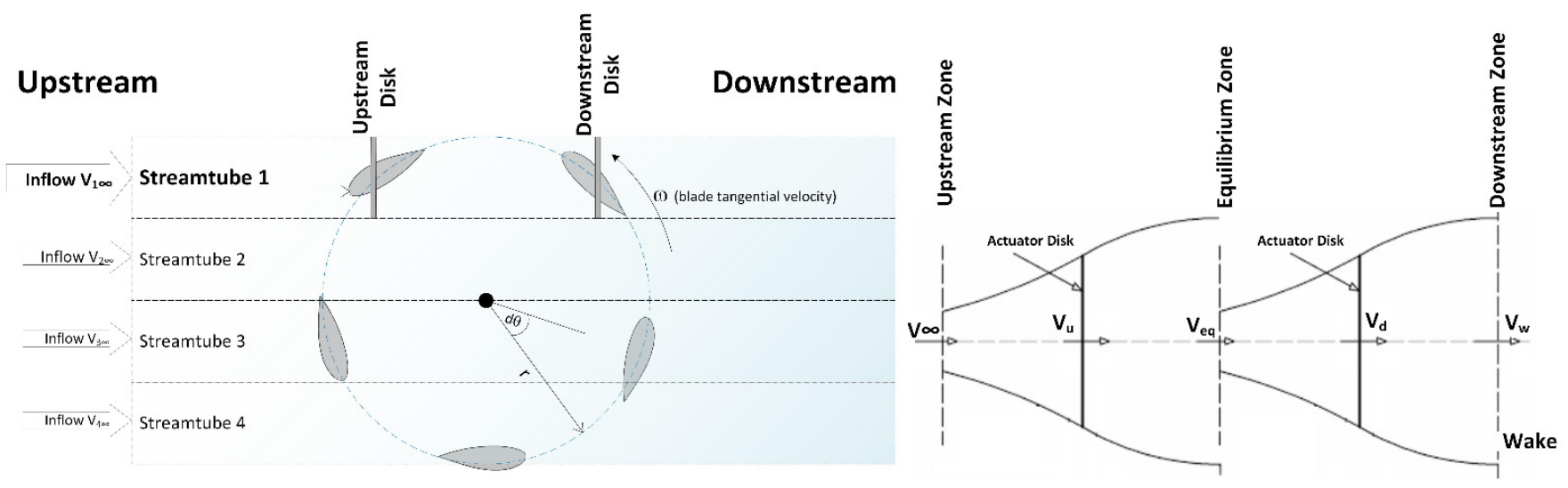

Figure 4. Double multiple stream tube model.

\subsection{Effect of Design Parameters on Power Output}

Several studies [38-43], have been carried out in past to study the effects of variation in various design parameters of $\mu$ VAWT. These studies have used a variety of techniques to improve turbine performance.

In the current study, the effect of each design variable on $C_{P}$ as a function of $\lambda$, the tip speed ratio (TSR), is studied using the blade element momentum theory [44]. Each parameter is varied while keeping all others constant. Using the results calculated for each design parameter, the design is formulated using the best value of each parameter (intuitive approach). The geometric restrictions (geographical constraints) and simplicity requirements (manufacturing and economic constraints) are maintained, as the aim of the study is to meet the requirements of the remote mountain regions. This back-to-the-basics approach keeps the design process simple, cost-effective, and results in an easy-to-maintain turbine. In these remote areas, traveling to a settled region for repairs, etc., is a very costly and difficult endeavor. Thus, design simplicity is as important as performance.

\subsubsection{Effect of Airfoil Type}

The airfoil design is the most important variable affecting turbine performance [37]. The design of an airfoil is dependent on its thickness, camber, and camber location. These 
variables are altered individually to study each one's impact on the turbine performance. Before the National Advisory Committee for Aeronautics (NACA) formulated the NACA airfoil series, the airfoil design was not standardized, and researchers had to rely on their intuition and experience to determine the geometric characteristics of the airfoil. The NACA airfoil series has been designed using algebraic equations and provides researchers with much-needed details of airfoil performance. The NACA four-digit series airfoil profile is defined by a numbering system where:

- Digit 1 gives the maximum camber as a percentage of the chord length.

- Digit 2 gives the distance of maximum camber from the airfoil leading edge $(10 \times$ digit in percent of chord length).

- Digits $3 \& 4$ give the maximum thickness of the airfoil as a percent of the chord.

\subsubsection{Effect of Airfoil Thickness on $C_{P}$}

Traditionally, the NACA four digits and symmetric airfoil are used for most Darrieus type turbine designs [30]. Airfoils with different thicknesses are explored and their influence on $\mathrm{C}_{\mathrm{P}}$ is studied.

Figure 5 shows that turbine performance is not affected much by the thickness of airfoil; however, if the thickness increases (such as in the case of NACA 0021), the coefficient of power $C_{P}$ starts decreasing because of the increase in the blunt-body drag. Similarly, using very thin airfoil can lead to structural and manufacturing concerns.

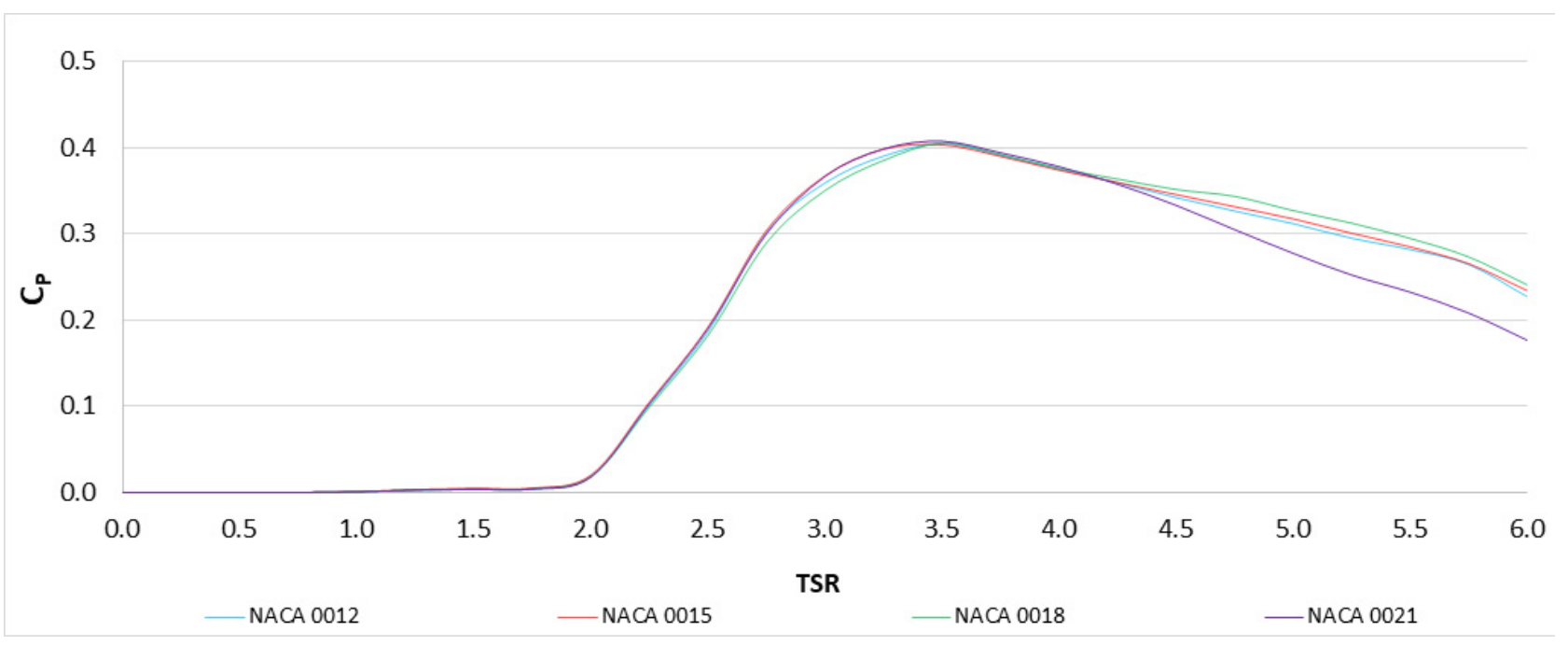

Figure 5. Coefficient of power vs. TSR plot for different airfoil thickness.

Considering these constraints, NACA 0018 is selected for further studies for having better $C_{P}$ at higher TSR values compared to NACA 0021. Moreover, it provides better structural strength when compared with NACA 0012 or 0015.

\subsubsection{Effect of Airfoil Camber}

Different cambers are introduced to the selected airfoil thickness of $18 \%$ to study the effect of variation of airfoil camber. Figure 6 shows that the performance of the highly cambered airfoil is better at low TSR values, hence it can be useful for resolving self-starting issues. However, the largest $C_{P}$ is reduced for the turbine at higher TSR values for the cambered airfoil. Therefore, the introduction of the camber would deteriorate the overall turbine performance. Hence, the choice of symmetric airfoil NACA 0018 is kept for this design as it also satisfies the manufacturing and economic concerns. 


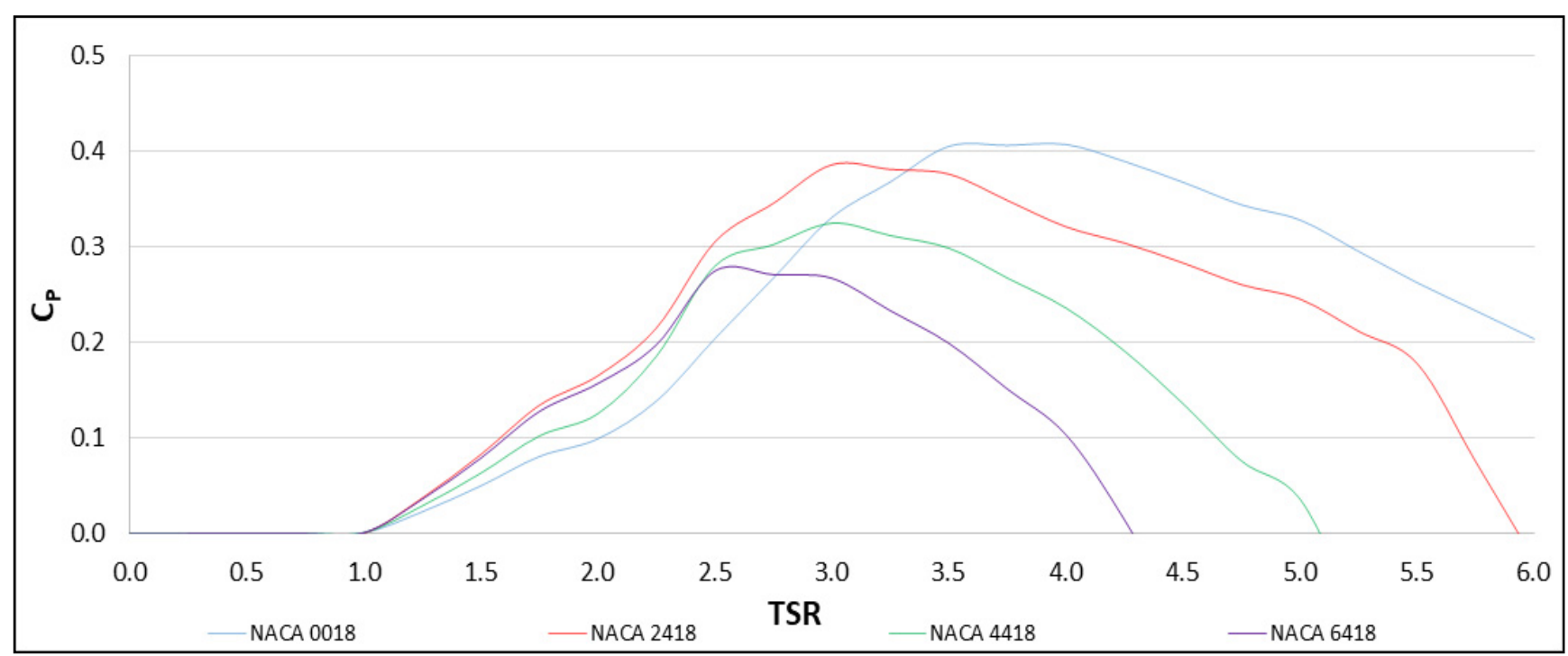

Figure 6. Coefficient of power vs. TSR plot for different airfoil camber.

\subsubsection{Effect of Number of Blades}

A turbine performance with 3, 4, 5, 6, and 7 blades is studied. The results show better $C_{P}$ values at low TSR values for a turbine with a greater number of blades. It is seen that maximum $C_{P}$ values increase as the number of blades increase. However, the turbine performance readily decreases at higher values of TSR when the turbine solidity increases as more than 5 blades are included in the design.

The analysis of the effect of several blades revealed that the increase in the number of blades improved the turbine efficiency at a low tip-speed ratio, and a higher maximum output was also obtained at the lower TSR values. It was further observed that the $C_{P}$ vs. TSR curve was flatter for the lower number of blades, near the maximum values of $C_{P}$, which corresponds to less change in power output and better off-design performance as well. Based on the data in Figure 7, it was seen that the turbine with 5 blades keeps higher power output with a $C_{P}$ value of 0.35 to 0.4 for a longer duration within the expected range of TSR variation. Hence, it was concluded that fewer blades not only helped in reducing the overall cost of the turbine manufacturing but also improved the off-design performance. The 5-bladed turbine design was therefore selected for the study.

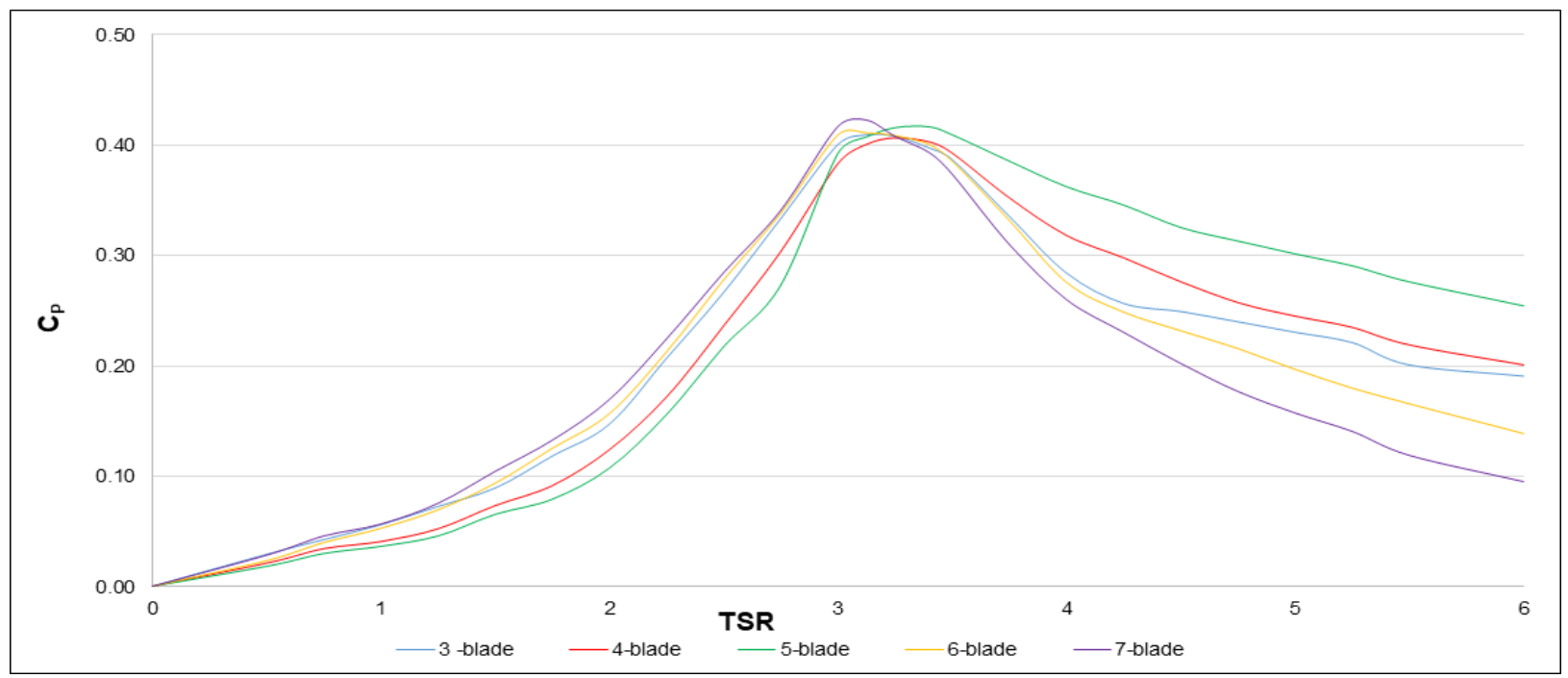

Figure 7. Coefficient of power vs. TSR plot for the different number of blades. 


\subsubsection{Effect of the Airfoil Chord Length}

The airfoil chord length has a major impact on the turbine performance because it governs the surface area of the blade, hence the values of drag and lift forces. A turbine with different chord lengths is analyzed and the following observations are made:

- Decreasing chord length improves the maximum value of $C$.

- The moderate value of chord length gives better performance at TSR values $<4.5$.

- Larger chord lengths tend to reduce the maximum $C_{P}$ and turbine performance decreases rapidly at higher TSR values.

From the data depicted in Figure 8, the best turbine performance $\left(C_{P}\right)$ for most TSR values is achieved for a chord length of $125 \mathrm{~mm}$, and therefore, this value is selected for the study.

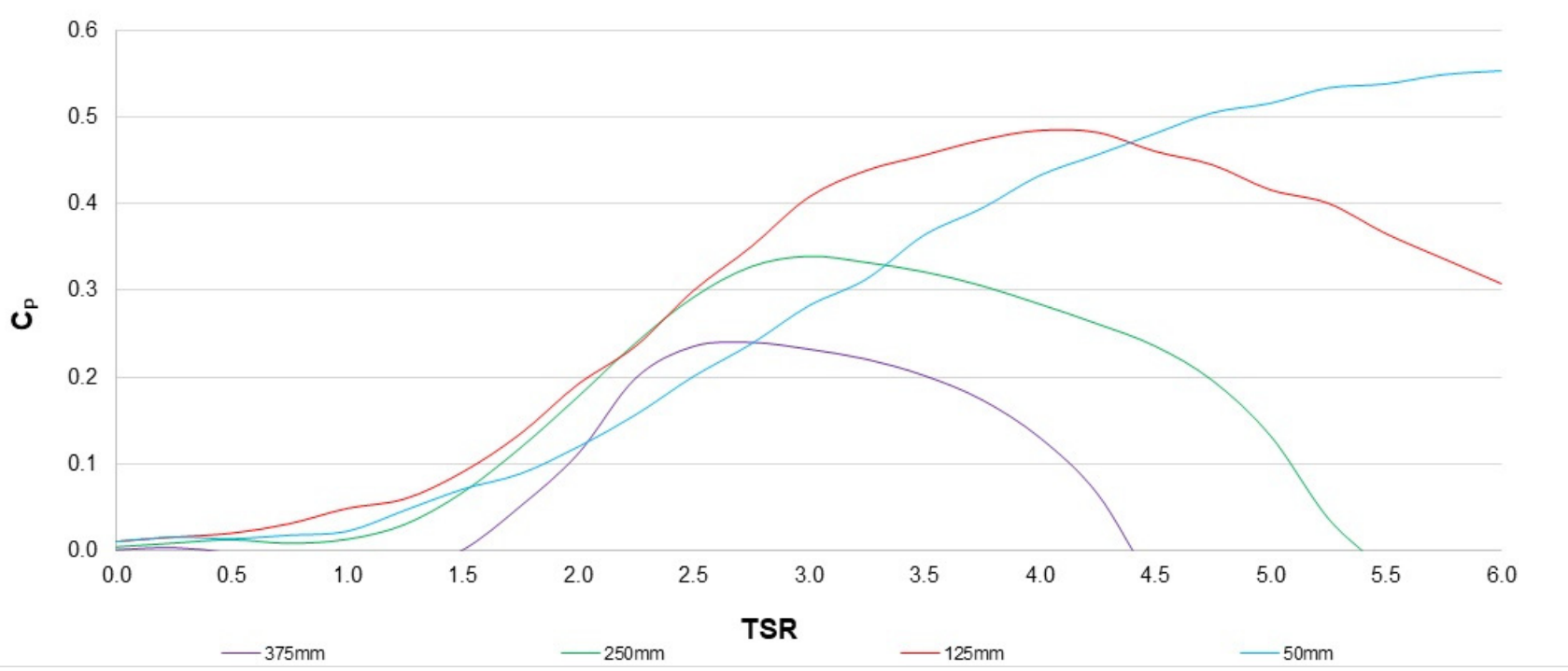

Figure 8. Coefficient of power vs. TSR plot for different chord lengths.

\subsubsection{Effect of Turbine Radius}

The radius $(\mathrm{R})$ of the turbine is not only governed by performance parameters but also according to the available width of the water channel. Turbines with a bigger radius have stable behavior near largest $C_{P}$, but poor performance at low TSR. From the results shown in Figure 9, the radius of $0.750 \mathrm{~m}$ is selected as it supplies a good value of $C_{P}(0.35$ to 0.40 ) for the required TSR range.

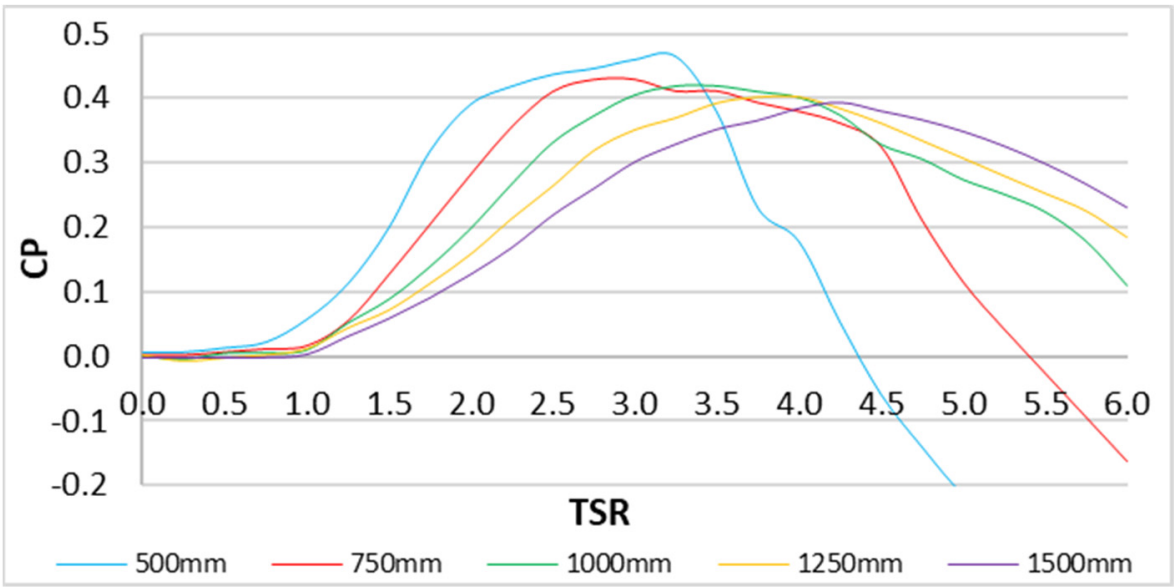

Figure 9. Coefficient of power vs. TSR plot for different turbine radii. 


\subsubsection{Effect of Pitch Angle}

The pitch control mechanism is quite complex to design. Variable pitch gives improved performance and stable torque output [45], but on the other hand, it increases system complexity $[46,47]$. Therefore, the fixed-pitch design is selected for experimental testing. Results are obtained for different fixed-pitch angles, as shown in Figure 10, to select the angle for best performance.

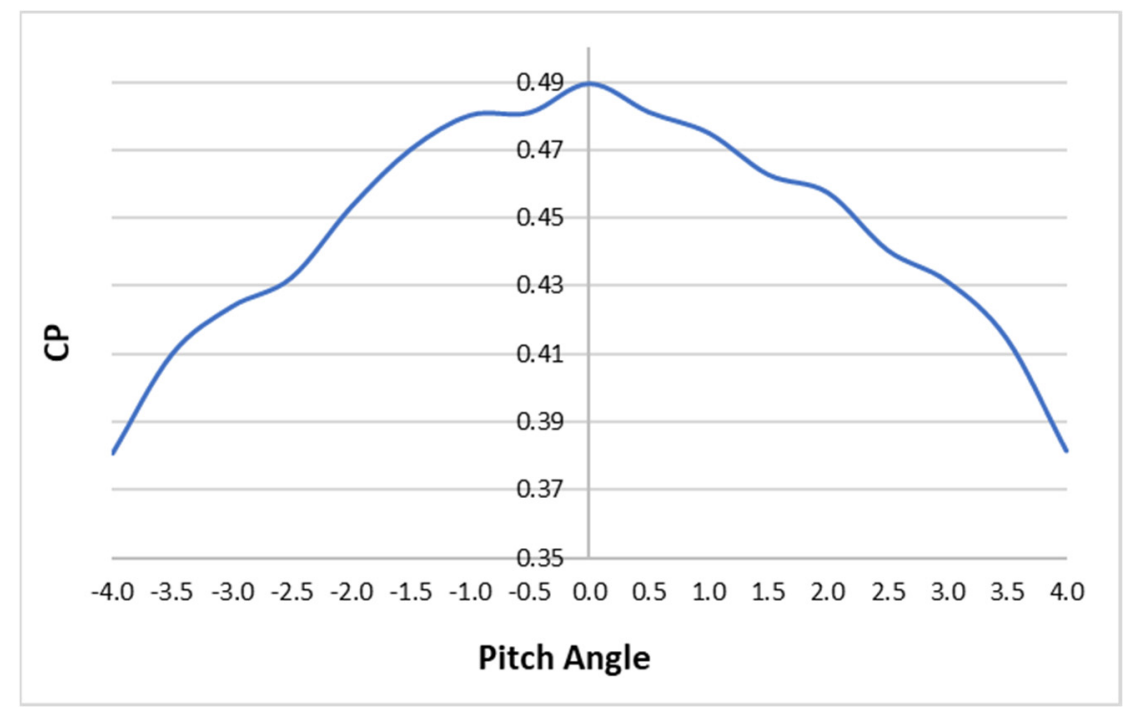

Figure 10. Coefficient of power vs. blade pitch angle.

Based on the data in Figure 10 above, it was seen that the zero degrees pitch angle gives maximum power out. Hence, a zero-pitch angle is selected for the design.

\subsubsection{Effect of Turbine Height}

The height of the turbine is a design constraint governed by the depth of the water channel and it has an almost linear relation with $C_{P}$.

Based on the data seen in Figure 11 above, it was seen that, as expected, $C_{P}$ increases almost linearly with the increase of turbine height, as the blade surface area is directly proportional to the turbine height. However, considering the available height constraint during off-peak season in the water channels under consideration, a height of $0.75 \mathrm{~m}$ is selected for the design to ensure year-round stable power output.

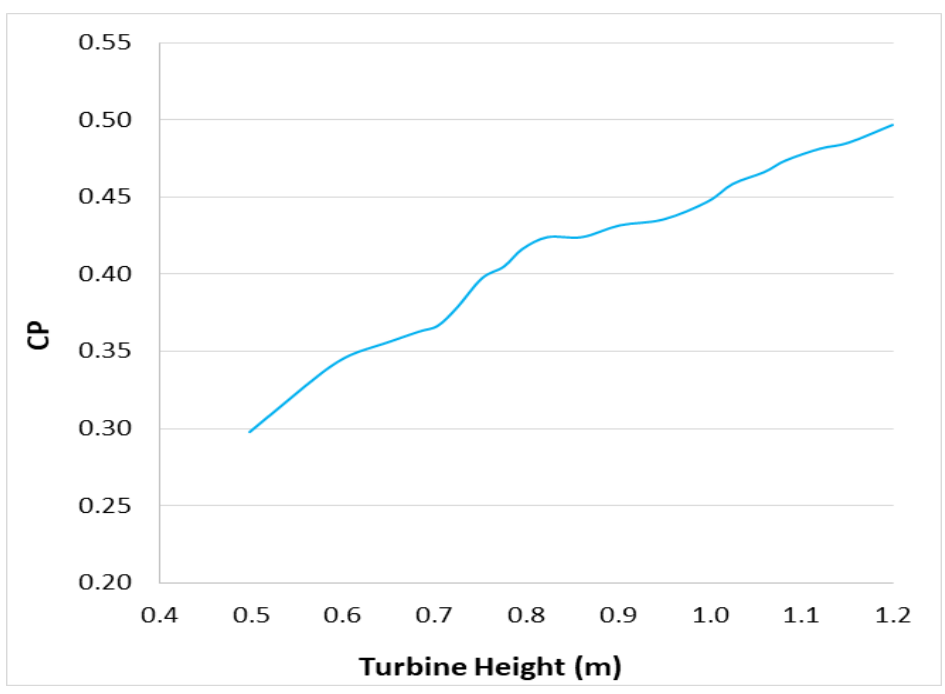

Figure 11. Coefficient of power vs. turbine height. 


\section{Final Design Selection}

Based on the above-mentioned studies, and keeping in mind the geographical and economic constraints, the following design parameters as depicted in Table 2 are selected for further analysis.

Table 2. Final selected design parameters for the vertical axis water turbine.

\begin{tabular}{cc}
\hline Airfoil & NACA 0018 \\
\hline Chord length & $0.125 \mathrm{~m}$ \\
Number of blades & 5 \\
Height & $0.75 \mathrm{~m}$ \\
Radius & $0.75 \mathrm{~m}$ \\
Pitch angle & $0 \mathrm{deg}$ \\
\hline
\end{tabular}

Power Output of Selected Design

The $C_{P}$ and power output curves of the finalized design are given in Figures 12 and 13 below:

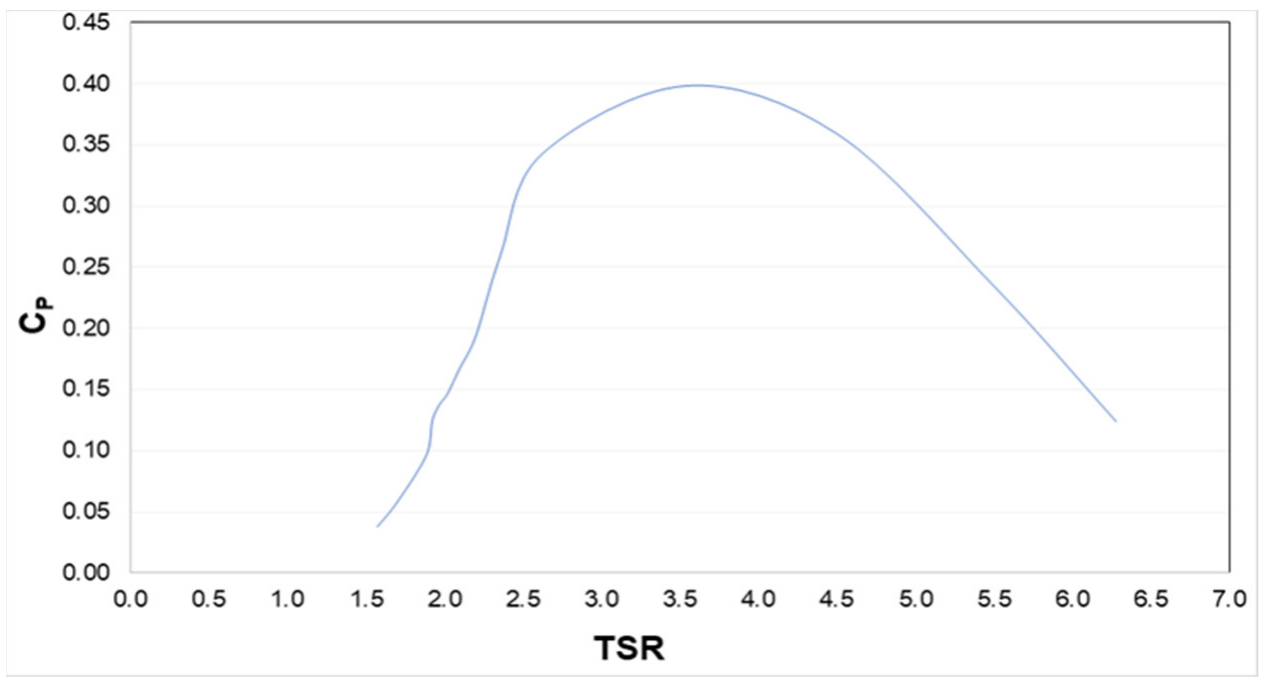

Figure 12. $C_{P}$ Vs. TSR for selected turbine design.

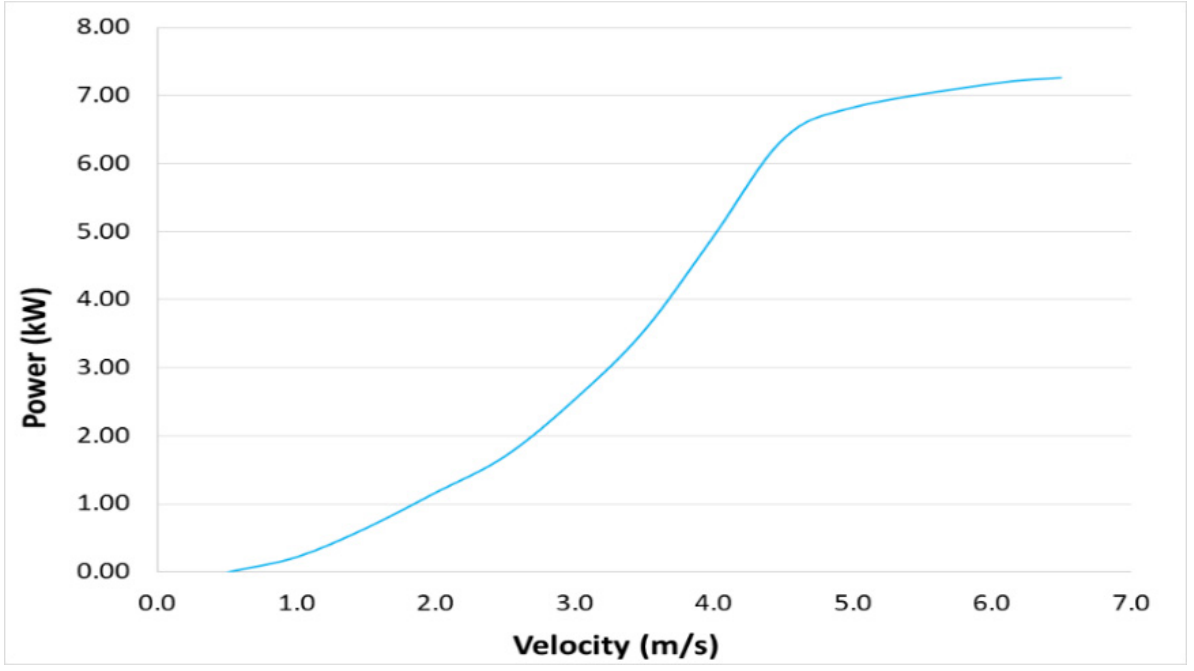

Figure 13. Power output vs. velocity for selected turbine design. 
The results show that selecting turbine design based on the best performance of each parameter (within the given constraints) can give a good year-round performance. It is seen that turbine performance stays stable within a range of $2.5<\mathrm{TSR}<4.5$ and power out of $4 \mathrm{~kW}$ to $6.5 \mathrm{~kW}$ is achieved in a velocity range of $3.5<\mathrm{V}<4.5 \mathrm{~m} / \mathrm{s}$ which is available during the summer months. However, during the winter months, the power output is likely to remain close to $2 \mathrm{~kW}$ only.

\section{Fabrication of Turbine}

Turbine blades are fabricated by using a five-axis CNC machine using polystyrene as the base material and later coated with polyurethane material. Five inch diameter circular aluminum plates are mounted on top of each blade to avoid tip vortices.

Each blade was mounted by two threaded rods and nuts (Figure 14) on the star-shaped structure with five arms and a central shaft (Figure 15). This arrangement ensured the required rigidity of the blades. A heavy metal structure was made using stainless steel beams to hold the turbine with the ground clearance of one foot. The CAD drawings of the assembly process are shown in Figure 15.
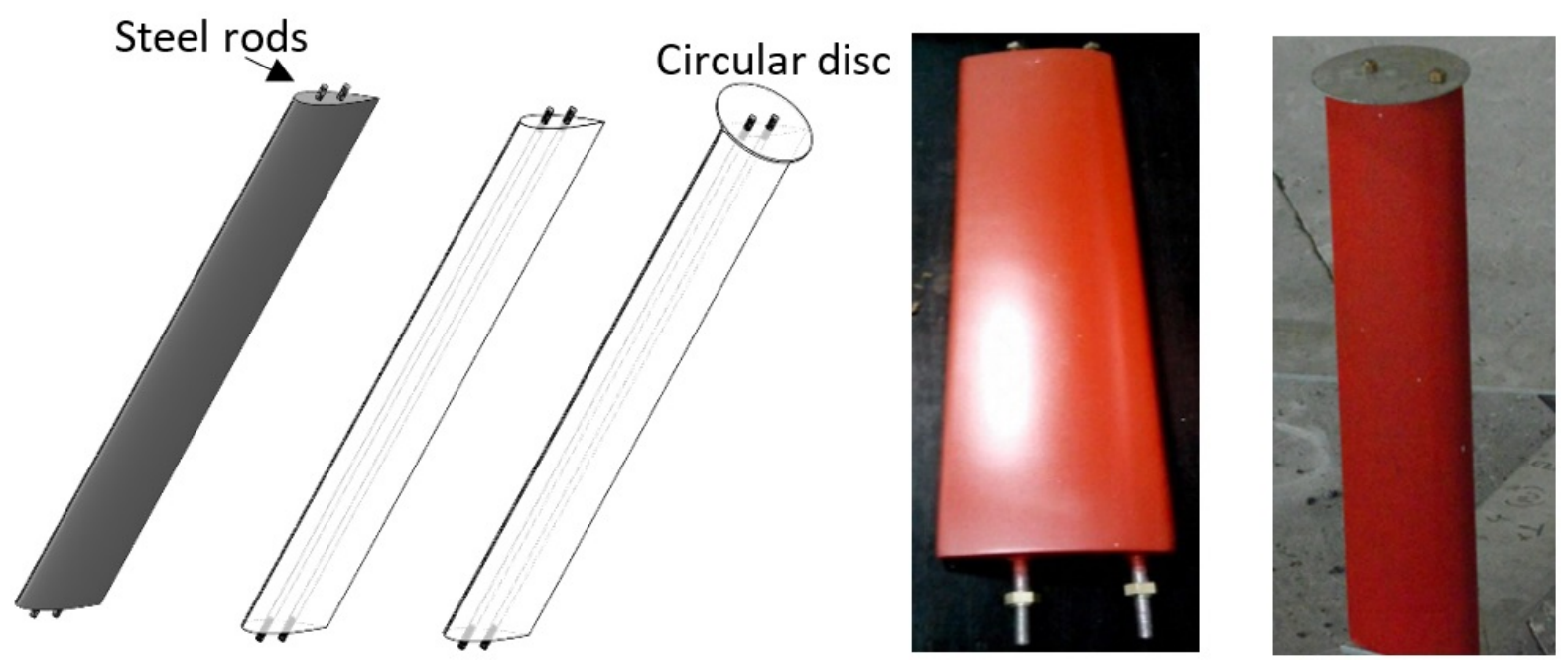

Figure 14. CAD drawings and pictures of turbine blades.

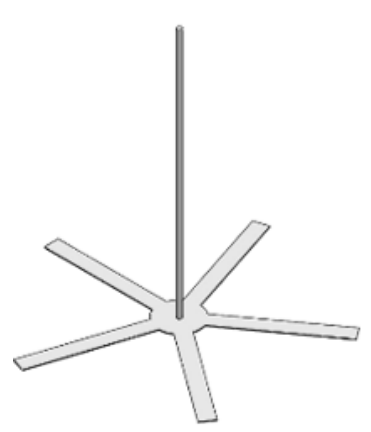

(a)

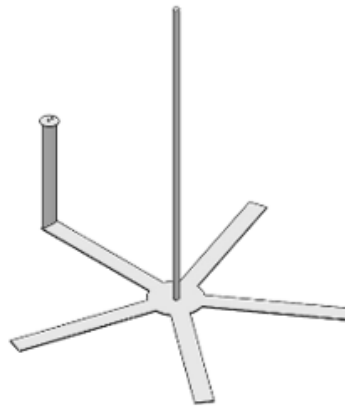

(b)

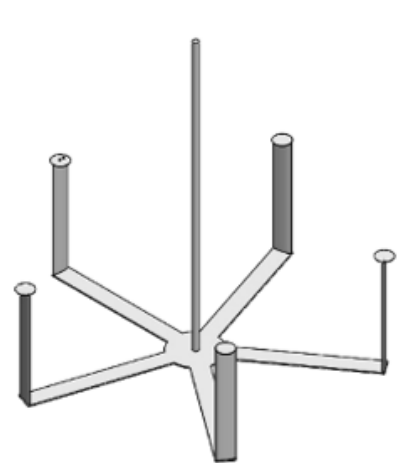

(c)

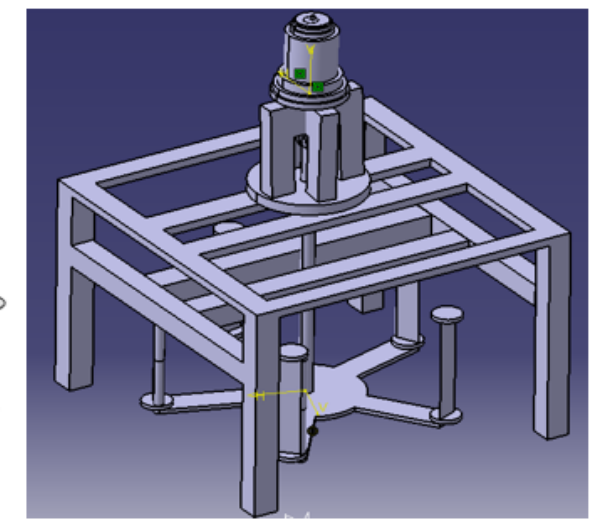

(d)

Figure 15. (a-c) Assembly steps of the turbine, (d) complete assembly CAD.

The complete turbine support structure and hub assembly were fabricated using angle iron and stainless-steel pipes, and the actual turbine assembly is shown in Figure 16. 


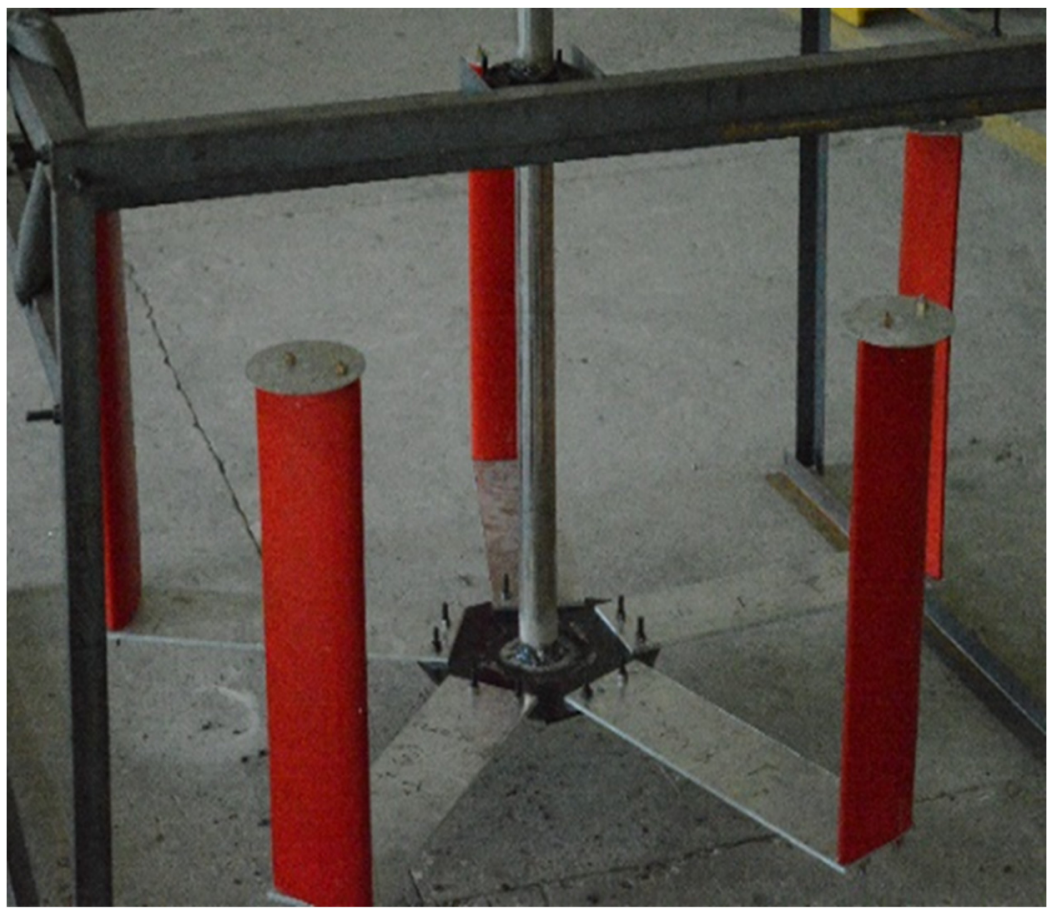

Figure 16. The assembled turbine.

\section{Experimental Testing}

\subsection{Site Selection}

The testing site selected is located at Kalpani River (34.073808, 72.022975), Khyber Pakhtunkhwa, Pakistan. The testing of the turbine, instead of being conducted in a controlled environment, was conducted in an actual water stream, with similar characteristics as the mountain streams in the region of interest, where accurate measurement was not possible. This resulting uncertainty may be questioned from a strictly scientific perspective; however, as the turbines are to be deployed in a real-world environment, which is uncontrolled and unpredictable, authors feel that this provides a better viability study. The turbine was tested at three different sites with different flow velocities and channel depths, as shown in Table 3.

Table 3. The data of three sites were selected for the testing of the vertical axis water turbine.

\begin{tabular}{lcccc}
\hline & Velocity & Channel Depth & Channel Width & Height of Blade Immersed in Water \\
\hline Site 1 & $1.50 \mathrm{~m} / \mathrm{s}$ & $1.10 \mathrm{~m}$ & $22.5 \mathrm{~m}$ & $0.75 \mathrm{~m}$ \\
Site 2 & $1.67 \mathrm{~m} / \mathrm{s}$ & $1.00 \mathrm{~m}$ & $22.5 \mathrm{~m}$ & $0.75 \mathrm{~m}$ \\
Site 3 & $1.67 \mathrm{~m} / \mathrm{s}$ & $0.65 \mathrm{~m}$ & $22.5 \mathrm{~m}$ & $0.50 \mathrm{~m}$ \\
\hline
\end{tabular}

\subsection{Velocity \& Force Measurement}

Water velocity was measured using the simple float method. The time to travel $10 \mathrm{~m}$ by a float (Styrofoam piece) was noted multiple times using a stopwatch and the average taken as time $t$. Velocity was simply calculated as $\frac{10 m}{t}$. For force measurement, a spring balance attached to a turbine blade was used and the brake force $(\mathrm{F})$ needed to keep the turbine at rest was measured. Force (F) measured by the spring balance is used for torque and power calculations.

$$
C_{m}=r \times C_{T}
$$

where $C_{T}$ is the coefficient of the tangential force generated on the turbine blades, and $C_{m}$ is the coefficient of the moment of the turbine. Then from Equation (6);

$$
C_{P}=\lambda \times C_{m}
$$




$$
\begin{gathered}
\tau=\frac{1}{2} \rho V_{\infty}^{2} A_{r e f} C_{m} \\
P_{\text {out }}=\tau \times \omega
\end{gathered}
$$

\section{CFD Analysis}

Computational fluid dynamics (CFD) analysis of our design was carried out to achieve better insight into the fluid flow through the turbine. The turbine was modeled as a rotating mesh domain within the static flow domain. For the CFD analysis, a 2D model of the micro VAWT was created. Five equally spaced blades were placed on the turbine periphery. NACA 0018 symmetric blades $0.125 \mathrm{~m}$ chord length was used, and the turbine radius was selected to be $0.75 \mathrm{~m}$ (as per Table 3 parameters). ICEM CFD modeling software was used to create a 2D model of the turbine. The mesh was created and read into an ANSYS Fluent solver. The flow domain was selected to be a $30 \mathrm{~m}-b y-30 \mathrm{~m}$ square domain. The CFD domain and turbine model are shown in Figure 17. While the computational mesh is shown in Figure 18.

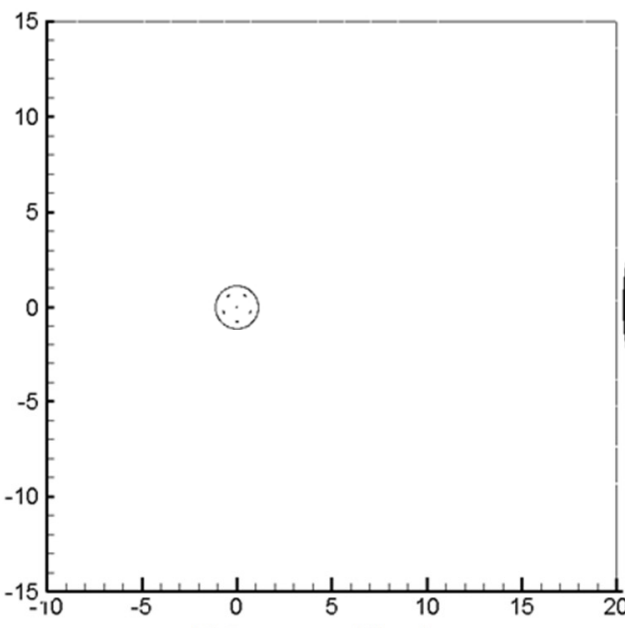

(a) Computational flow domain

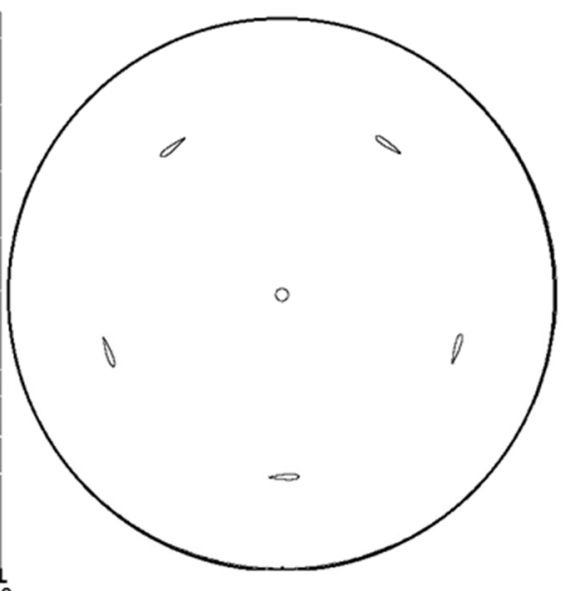

(b) Inner rotating turbine domain

Figure 17. (a) The CFD domain and (b) the turbine model.

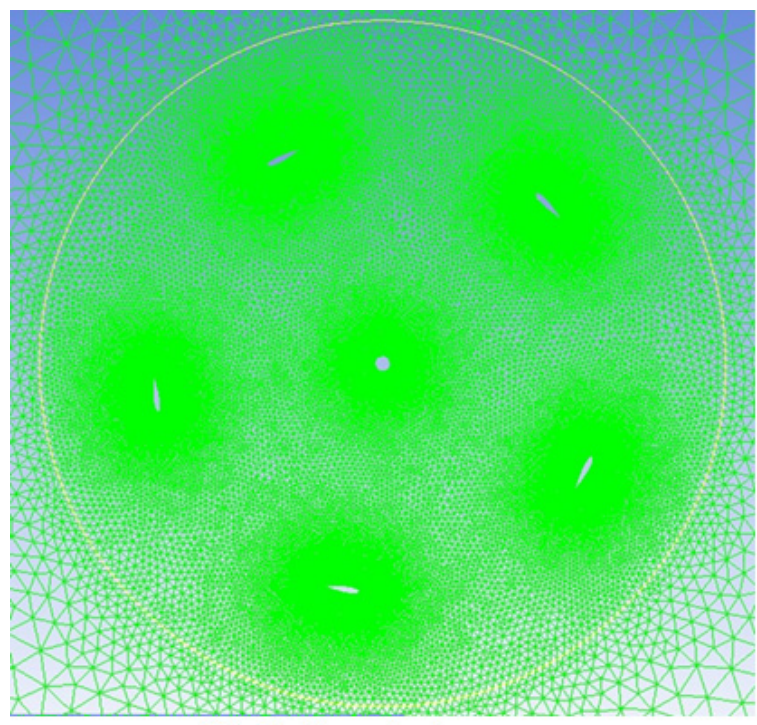

(a) Turbine wheel areas

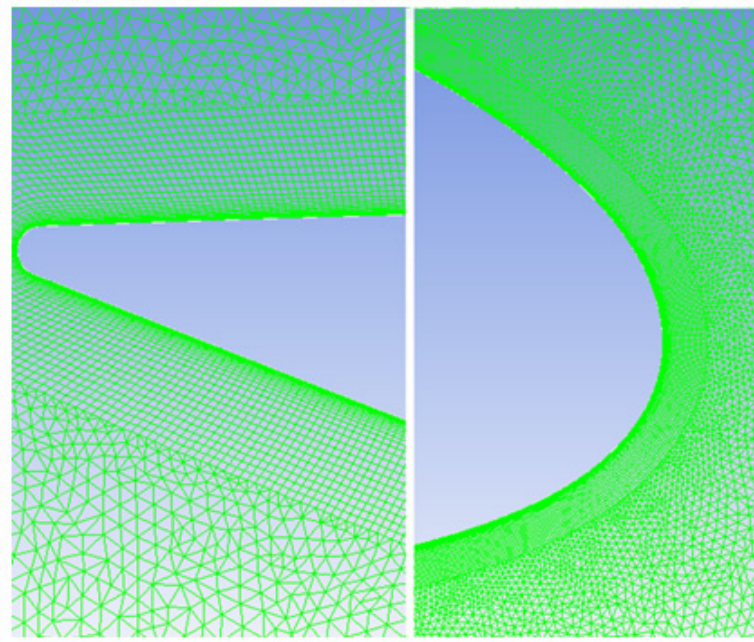

(b) Blade trailing edge

(c) Blade leading edge

Figure 18. Selected CFD mesh: (a) turbine wheel area, (b) blade trailing edge, and (c) blade leading edge. 
Mesh independence was conducted using mesh sizes as given in Table 4 below. The turbine is modeled as a rotating mesh domain within the static flow domain. This study simulates flow over the turbine using the shear stress transport (SST k-omega) turbulence model. Flow conditions of Site 1 were used during the mesh independence simulations. The simulations were run for 29 turbine revolutions to ensure that stabilized data was achieved.

Table 4. Mesh independence data.

\begin{tabular}{cc}
\hline Mesh Size (Nodes) & $\mathbf{C}_{\mathbf{m}}$ \\
\hline 588,111 & 0.1607 \\
648,681 & 0.1791 \\
729,756 & 0.1805 \\
\hline
\end{tabular}

Based on the data in Table 4, the mesh size of 648,681 nodes was selected. The selected mesh is depicted in Figure 18.

Time step independence study was also carried out. Based on the data in Table 5, the Time-step of $0.00284091 \mathrm{~s}$ (representing an increment of $0.75 \mathrm{deg}$ in the azimuthal angle per time-step) was selected.

Table 5. Time-step (Tstep) independence data.

\begin{tabular}{ccc}
\hline Time-Step (s) & deg/Tstep & $\mathbf{C}_{\mathbf{m}}$ \\
\hline 0.00378789 & 1.00 & 0.1588 \\
0.00284091 & 0.75 & 0.1803 \\
0.00189394 & 0.50 & 0.1812 \\
\hline
\end{tabular}

\section{Discussion on CFD Results}

For torque calculations, the total coefficient of the moment $\left(C_{m}\right)$ was calculated by adding the individual blade $C_{m}$ for all the five blades and the turbine hub structure at each iteration, and then taking the average of the total $C_{m}$ over a complete turbine rotation cycle of $360^{\circ}$. The $C_{m}$ of each blade, total turbine $C_{m}$, and the average value of $C_{m}$, are shown in Figure 19. The turbine torque and power are calculated using equations (8) and (9).

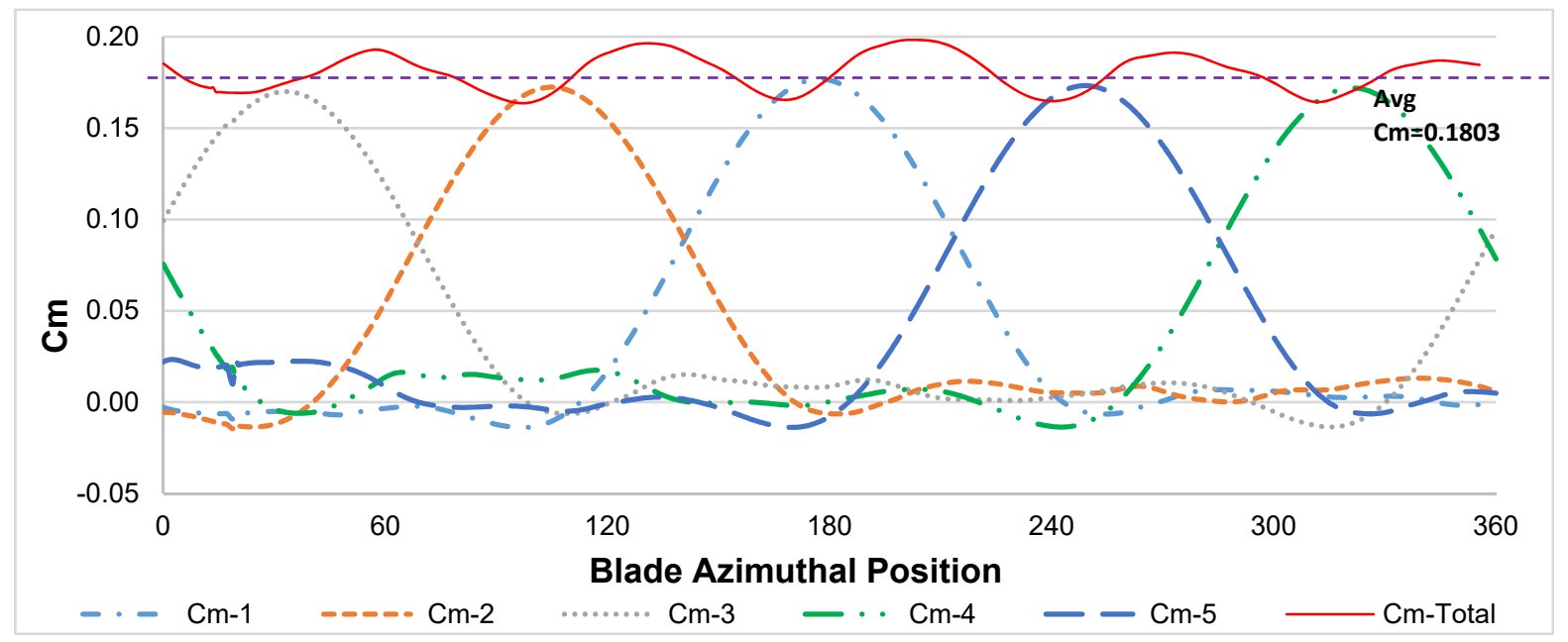

Figure 19. Turbine coefficient of the moment for individual blades and total turbine $C_{m}$.

The velocity profiles obtained using CFD simulation for the case with a river inflow rate of $1.5 \mathrm{~m} / \mathrm{s}$ and turbine rotation rate of 44 RPM are depicted in Figure 20, while the vorticity distribution is shown in Figure 21. 


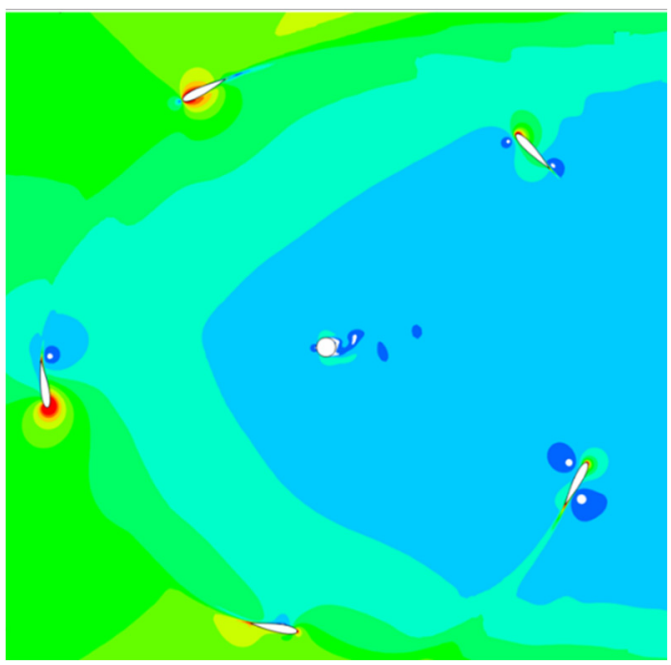

Figure 20. Velocity profile obtained using CFD simulation of river inflow at $1.5 \mathrm{~m} / \mathrm{s}$ and turbine rotation rate of $44 \mathrm{RPM}$.

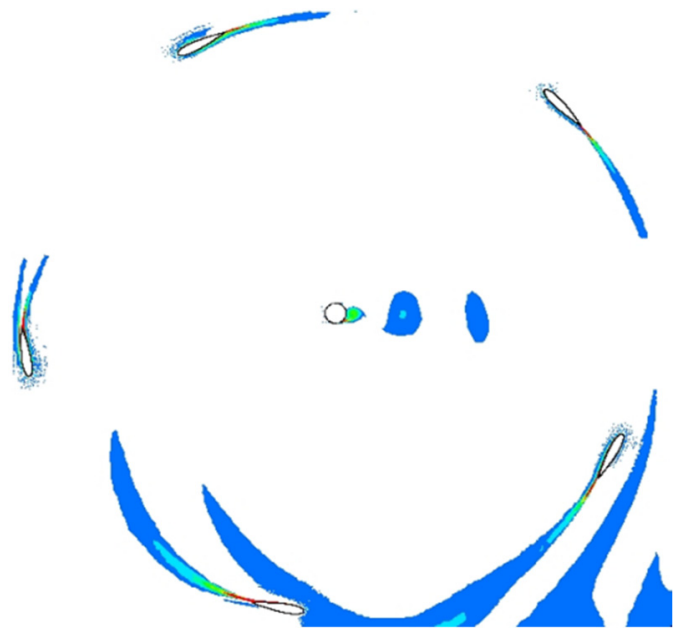

Figure 21. Vorticity profile obtained using CFD simulation of river inflow at $1.5 \mathrm{~m} / \mathrm{s}$ and turbine rotation rate of $44 \mathrm{RPM}$.

\section{Comparison of Results}

The results obtained using CFD analysis and QBlade (double multiple stream tube model) are compared with experimental results in Table 6.

Table 6. The comparison of experimental and theoretical results of site 1 and site 2 .

\begin{tabular}{cccccccccccc}
\hline \multicolumn{4}{l}{ DMST Model Results } & \multicolumn{3}{c}{ Experimental Results } & \multicolumn{2}{c}{ CFD Results } & \multicolumn{2}{c}{ Difference } \\
\hline Site & $\begin{array}{c}\text { Vel } \\
(\mathbf{m} / \mathbf{s})\end{array}$ & RPM & $\begin{array}{c}\text { Power } \\
\text { output } \\
\text { (Watts) }\end{array}$ & RPM & $\begin{array}{c}\text { Measured } \\
\text { force (N) }\end{array}$ & $\begin{array}{c}\text { Torque } \\
\text { (N-m) }\end{array}$ & $\begin{array}{c}\text { Power } \\
\text { output } \\
\text { (Watts) }\end{array}$ & RPM & $\begin{array}{c}\text { Power } \\
\text { output } \\
\text { (Watts) }\end{array}$ & $\begin{array}{c}\text { Expt. } \\
\text { vs. } \\
\text { DMST }\end{array}$ & $\begin{array}{c}\text { Expt. } \\
\text { vs. } \\
\text { CFD }\end{array}$ \\
\hline 1 & 1.5 & 51 & 670 & 44 & 147 & 110.3 & 508 & 44 & 524.1 & $24.20 \%$ & $3.10 \%$ \\
2 & 1.7 & 57 & 950 & 48 & 209 & 156.8 & 787.9 & 48 & 799.5 & $17.10 \%$ & $1.50 \%$ \\
\hline
\end{tabular}

\section{Conclusions}

The results of this study show that the designed $\mu$ VAWT produces approximately $0.5 \mathrm{~kW}$ of electricity. As the calculation was accomplished taking the least flow rates among the available water channels in the off-peak season, it can be considered that this would be 
the minimum electricity generation year-round. If $85 \%$ serviceability is assumed for the turbine, the minimum power generation is expected to be $7325 \mathrm{kWh}$ annually. The area occupied by the microturbine is $1.77 \mathrm{~m}^{2}$. This translates to a power generation density of around $2100 \mathrm{kWh} /$ year $/ \mathrm{m}^{2}$. The power density of the proposed design compares favorably with other possible options [48] and the design has minimal adverse environmental effects as it does not cause any emissions, pollution, or disturbance to streams ecology [20-23]. Hence, the proposed microturbine design is very workable for the population living around the water channels in the region.

The DMST based QBlade results in this study show a difference of $24.2 \%$ compared to the experimental values. The experimental values are lower as QBlade does not include the support and hub structure. The preliminary CFD results are found to be much closer to the experimental values as the turbine hub is also included in the model. However, a further detailed CFD analysis is needed to explain these differences. The research suggests that Darrieus rotor type vertical axis water microturbines, which can be easily fabricated with little expense, can be successfully used for power extraction from shallow water streams in mountain regions. Provision of cheap power to off-grid remote mountainous regions using micro VAWT can bring about great socioeconomic benefits [49] without causing any major disruption to the ecosystem [2,3]. Other renewables in these mountainous regions would have a larger footprint and would likely cause more disruption to the local ecosystem. Remote generation would entail the laying of transmission lines, which would damage the environment more severely.

This is a preliminary study carried out to ascertain that run-of-the-river power generation using $\mu$ VAWT is a viable option for a year-round supply of energy. The study uses the lowest flow rates among these water channels to do so. It is recommended that higher efficiency VAWT designs as have been investigated [45], along with tandem deployment of multiple turbines, be studied, so larger power requirements may also be met for populations residing in these remote areas. It is also suggested that more detailed parametric, sensitivity, and optimization analyses be carried out in future studies. The vortex interaction of the blades operating in the wake may be investigated in detail in the future.

Author Contributions: Conceptualization, S.R.S., S.H.R.S. and Z.K.; methodology, S.R.S.; software, S.H.R.S., U.R. and S.R.S.; validation, F.R., S.R.S. and M.F.S.; formal analysis, S.R.S.; investigation, S.R.S., S.H.R.S., M.B.K.N. and Z.K.; resources, F.R., H.Y., U.A.; data acquisition, S.R.S., U.R. and Z.K.; writing-original draft preparation, S.R.S. and S.H.R.S.; writing-review and editing, U.A., M.F.S., M.B.K.N. and H.Y.; visualization, S.H.R.S., and U.R.; supervision, S.R.S.; project administration, Z.K.; funding acquisition, H.Y., F.R. All authors have read and agreed to the published version of the manuscript.

Funding: This research did not receive any specific grant from funding agencies in the public, commercial, or not-for-profit sectors.

Institutional Review Board Statement: Not applicable.

Informed Consent Statement: Not applicable.

Acknowledgments: Efforts of Rida Waqar Shah, Abdullah Asad, Safdar Gohar, and Raja Ali Abbas are highly appreciated in conducting experimental testing.

Conflicts of Interest: The authors declare no conflict of interest.

\section{References}

1. Zou, C.; Zhao, Q.; Zhang, G.; Xiong, B. Energy Revolution: From a Fossil Energy Era to a New Energy Era. Nat. Gas Ind. B 2016, 3, 1-11. [CrossRef]

2. Álvarez, X.; Valero, E.; De La Torre-Rodríguez, N.; Acuña-Alonso, C. Influence of Small Hydroelectric Power Stations on River Water Quality. Water 2020, 12, 312. [CrossRef]

3. Quaranta, E.; Bonjean, M.; Cuvato, D.; Nicolet, C.; Dreyer, M.; Gaspoz, A.; Rey-Mermet, S.; Boulicaut, B.; Pratalata, L.; Pinelli, M.; et al. Hydropower Case Study Collection: Innovative Low Head and Ecologically Improved Turbines, Hydropower in Existing Infrastructures, Hydropeaking Reduction, Digitalization and Governing Systems. Sustainability 2020, 12, 8873. [CrossRef] 
4. Laghari, A.N.; Vanham, D.; Rauch, W. The Indus Basin in the Framework of Current and Future Water Resources Management. Hydrol. Earth Syst. Sci. 2012, 16, 1063-1083. [CrossRef]

5. Ahmad, Z.; Hafeez, M.; Ahmad, I. Hydrology of Mountainous Areas in the Upper Indus Basin, Northern Pakistan with the Perspective of Climate Change. Environ. Monit. Assess. 2011, 184, 5255-5274. [CrossRef] [PubMed]

6. Balduzzi, F.; Bianchini, A.; Ferrara, G.; Marten, D.; Pechlivanoglou, G.; Nayeri, C.N.; Paschereit, C.O.; Drofelnik, J.; Campobasso, M.S.; Ferrari, L. Three-Dimensional Aerodynamic Analysis of a Darrieus Wind Turbine Blade Using Computational Fluid Dynamics and Lifting Line Theory. In Volume 2A: Turbomachinery; ASME International: New York, NY, USA, 2017. [CrossRef]

7. Oluwatoyin, K.; Oluwasegun, A.; Alabi, A. Power Generation and Its Impacts on the Environment. J. Sci. Res. Rep. 2015, 7, 551-566. [CrossRef] [PubMed]

8. Jorgenson, A.K.; Longhofer, W.; Grant, D.; Sie, A.; Giedraitis, V. The Effects of Economic and Political Integration on Power plants Carbon Emissions in the Post-Soviet Transition Nations. Environ. Res. Lett. 2017, 12, 044009. [CrossRef]

9. Perera, F. Pollution from Fossil-Fuel Combustion Is the Leading Environmental Threat to Global Pediatric Health and Equity: Solutions Exist. Int. J. Environ. Res. Public Health 2017, 15, 16. [CrossRef]

10. Sovacool, B.K. The Avian and Wildlife Costs of Fossil Fuels and Nuclear Power. J. Integr. Environ. Sci. 2012, 9, 255-278. [CrossRef]

11. Lakatos, L.; Hevessy, G.; Kovács, J. Advantages and Disadvantages of Solar Energy and Wind-Power Utilization. World Futur. 2011, 67, 395-408. [CrossRef]

12. Jaber, S. Environmental Impacts of Wind Energy. J. Clean Energy Technol. 2014, 251-254. [CrossRef]

13. Georgilakis, P.S. Technical Challenges Associated with the Integration of Wind Power into Power Systems. Renew. Sustain. Energy Rev. 2008, 12, 852-863. [CrossRef]

14. Tummala, A.; Velamati, R.K.; Sinha, D.K.; Indraja, V.; Krishna, V.H. A Review on Small Scale Wind Turbines. Renew. Sustain. Energy Rev. 2016, 56, 1351-1371. [CrossRef]

15. Owusu, P.A.; Asumadu-Sarkodie, S. A Review of Renewable Energy Sources, Sustainability Issues and Climate Change Mitigation. Cogent Eng. 2016, 3, 1167990. [CrossRef]

16. Topić, D.; Vezmar, S.; Spajić, A.; Šljivac, D.; Jozsa, L. Positive and Negative Impacts of Renewable Energy Sources. Int. J. Electr. Comput. Eng. Syst. 2014, 5, 15-23.

17. Arnaiz, M.; Cochrane, T.; Calizaya, A.; Shrestha, M. A Framework for Evaluating the Current Level of Success of MicroHydropower Schemes in Remote Communities of Developing Countries. Energy Sustain. Dev. 2018, 44, 55-63. [CrossRef]

18. Kaunda, C.S.; Kimambo, C.Z.; Nielsen, T.K. Potential of Small-Scale Hydropower for Electricity Generation in Sub-Saharan Africa. ISRN Renew. Energy 2012, 2012, 1-15. [CrossRef]

19. Jenniches, S. Assessing the Regional Economic Impacts of Renewable Energy Sources-A Literature Review. Renew. Sustain. Energy Rev. 2018, 93, 35-51. [CrossRef]

20. Hirsch, A.; Parag, Y.; Guerrero, J. Microgrids: A Review of Technologies, Key Drivers, and Outstanding Issues. Renew. Sustain. Energy Rev. 2018, 90, 402-411. [CrossRef]

21. Mariam, L.; Basu, M.; Conlon, M.F. A Review of Existing Microgrid Architectures. J. Eng. 2013, 2013, 1-8. [CrossRef]

22. Ali, A.; Li, W.; Hussain, R.; He, X.; Williams, B.W.; Memon, A.H. Overview of Current Microgrid Policies, Incentives and Barriers in the European Union, United States and China. Sustainability 2017, 9, 1146. [CrossRef]

23. Hossain, E.; Kabalci, E.; Bayindir, R.; Perez, R. A Comprehensive Study on Microgrid Technology. Int. J. Renew. Energy Res. 2014, 4, 1094-1104. [CrossRef]

24. Khan, M.; Bhuyan, G.; Iqbal, M.; Quaicoe, J. Hydrokinetic Energy Conversion Systems and Assessment of Horizontal and Vertical Axis Turbines for River and Tidal Applications: A Technology Status Review. Appl. Energy 2009, 86, 1823-1835. [CrossRef]

25. Elbatran, A.H.; Yaakob, O.; Ahmed, Y.; Shabara, H. Operation, Performance and Economic Analysis of Low Head MicroHydropower Turbines for Rural and Remote Areas: A Review. Renew. Sustain. Energy Rev. 2015, 43, 40-50. [CrossRef]

26. Fraenkel, P.; Paish, O.; Bokalders, V.; Harvey, A.; Brown, A.; Edwards, R. Micro-Hydro Power: A Guide for Development Workers; IT Publications: London, UK, 1999; Available online: https: / /www.amazon.com/Micro-Hydro-Power-Guide-DevelopmentWorkers/Dp/1853390291 (accessed on 28 January 2021).

27. Chehouri, A.; Younes, R.; Ilinca, A.; Perron, J. Review of Performance Optimization Techniques Applied to Wind Turbines. Appl. Energy 2015, 142, 361-388. [CrossRef]

28. Howell, R.; Qin, N.; Edwards, J.; Durrani, N. Wind Tunnel and Numerical Study of a Small Vertical Axis Wind Turbine. Renew. Energy 2010, 35, 412-422. [CrossRef]

29. Chen, W.-H.; Chen, C.-Y.; Huang, C.-Y.; Hwang, C.-J. Power Output Analysis and Optimization of Two Straight-Bladed VerticalAxis Wind Turbines. Appl. Energy 2017, 185, 223-232. [CrossRef]

30. Shukla, V.; Kaviti, A.K. Performance Evaluation of Profile Modifications on Straight-Bladed Vertical Axis Wind Turbine by Energy and Spalart Allmaras Models. Energy 2017, 126, 766-795. [CrossRef]

31. Islam, M.; Ting, D.; Fartaj, A. Aerodynamic Models for Darrieus-Type Straight-Bladed Vertical Axis Wind Turbines. Renew. Sustain. Energy Rev. 2008, 12, 1087-1109. [CrossRef]

32. Beri, H.; Yao, Y. Double Multiple Streamtube Model and Numerical Analysis of Vertical Axis Wind Turbine. Energy Power Eng. 2011, 3, 262-270. [CrossRef]

33. Dai, Y.M.; Gardiner, N.; Sutton, R.; Dyson, P.K. Hydrodynamic Analysis Models for the Design of Darrieus-Type Vertical-Axis Marine Current Turbines. Proc. Inst. Mech. Eng. Part M J. Eng. Marit. Environ. 2011, 225, 295-307. [CrossRef] 
34. Hirsch, I.H.; Mandal, A.C. A Cascade Theory for the Aerodynamic Performance of Darrieus Wind Turbines. Wind Eng. 1987, 11, 164-175.

35. Paraschivoiu, I. Wind Turbine Design with Emphasis on Darrieus Concept, 1st ed.; Presses Internationales Polytechnique: Paris, France, 2002; Available online: https:/ / www.amazon.com/Turbine-Design-Emphasis-Darrieus-Concept/Dp/2553009313 (accessed on 28 January 2021).

36. Komass, T. Mathematical Modelling and Calculation of Vertical Axis Wind Turbine Pitch System Using Matlab Tools. AASCIT J. Energy 2015, 2, 9-15.

37. Bhutta, M.M.A.; Hayat, N.; Farooq, A.U.; Ali, Z.; Jamil, S.R.; Hussain, Z. Vertical Axis Wind Turbine-A Review of Various Configurations and Design Techniques. Renew. Sustain. Energy Rev. 2012, 16, 1926-1939. [CrossRef]

38. Ma, N.; Lei, H.; Han, Z.; Zhou, D.; Bao, Y.; Zhang, K.; Zhou, L.; Chen, C. Airfoil Optimization to Improve Power Performance of a High-Solidity Vertical Axis Wind Turbine at a Moderate Tip Speed Ratio. Energy 2018, 150, 236-252. [CrossRef]

39. Miller, M.A.; Duvvuri, S.; Brownstein, I.; Lee, M.; Dabiri, J.O.; Hultmark, M. Vertical-Axis Wind Turbine Experiments at Full Dynamic Similarity. J. Fluid Mech. 2018, 844, 707-720. [CrossRef]

40. Li, Q.; Maeda, T.; Kamada, Y.; Murata, J.; Furukawa, K.; Yamamoto, M. Effect of Number of Blades on Aerodynamic Forces on a Straight-Bladed Vertical Axis Wind Turbine. Energy 2015, 90, 784-795. [CrossRef]

41. Brusca, S.; Lanzafame, R.; Messina, M. Design of a Vertical-Axis Wind Turbine: How the Aspect Ratio Affects the turbine's Performance. Int. J. Energy Environ. Eng. 2014, 5, 333-340. [CrossRef]

42. Bedon, G.; Castelli, M.R.; Benini, E. Optimization of a Darrieus Vertical-Axis Wind Turbine Using Blade Element-Momentum Theory and Evolutionary Algorithm. Renew. Energy 2013, 59, 184-192. [CrossRef]

43. Ferreira, C.S.; Barone, M.F.; Zanon, A.; Kemp, R.; Giannattasio, P. Airfoil Optimization for Stall Regulated Vertical Axis Wind Turbines. In Proceedings of the 33rd Wind Energy Symposium, Kissimmee, FL, USA, 5-9 January 2015. [CrossRef]

44. Marten, D.; Wendler, J. QBlade Guidelines v0.6. 2013. Available online: http://q-blade.org/project_images/files/guidelines_v06. pdf (accessed on 10 April 2015).

45. Sheikh, S.R.; Koreshi, Z.U.; Rauf, U.; Khalil, S.; Aziz, U. A Novel Blade-Pitching Mechanism Design and Testing for Micro Vertical-Axis Water Turbines. Tech. J. 2020, 25, 61-68.

46. Hwang, I.S.; Lee, Y.H.; Kim, S.J. Optimization of Cycloidal Water Turbine and the Performance Improvement by Individual Blade Control. Appl. Energy 2009, 86, 1532-1540. [CrossRef]

47. Elkhoury, M.; Kiwata, T.; Aoun, E. Experimental and Numerical Investigation of a Three-Dimensional Vertical-Axis Wind Turbine with Variable-Pitch. J. Wind. Eng. Ind. Aerodyn. 2015, 139, 111-123. [CrossRef]

48. Fuentes, J.E.; Moya, F.D.; Montoya, O.D. Method for Estimating Solar Energy Potential Based on Photogrammetry from Unmanned Aerial Vehicles. Electronics 2020, 9, 2144. [CrossRef]

49. Sheikh, S.R.; Sheikh, H.; Koreshi, Z.U. Emerging Smart Community Concept and Microgrid Technology—A Study of Lagging Skill Development in Pakistan. Int. J. Train. Res. 2019, 17 (Suppl. S1), 170-181. [CrossRef] 